CLINICAL STUDY

\title{
Effect of pioglitazone on serum concentrations of osteoprotegerin in patients with type 2 diabetes mellitus
}

\author{
Jong Suk Park ${ }^{1,2}$, Min Ho Cho ${ }^{1}$, Ji Sun Nam ${ }^{1}$, Jeong Seon Yoo ${ }^{1}$, Chul Woo Ahn ${ }^{1,2}$, Bong Soo Cha ${ }^{1}$, Kyung Rae Kim ${ }^{1}$ \\ and Hyun Chul Lee ${ }^{1}$ \\ ${ }^{1}$ Division of Endocrinology, Department of Internal Medicine, Kangnam Severance Hospital and ${ }^{2}$ Severance Institute for Vascular and Metabolic Research, \\ Yonsei University College of Medicine, 146-92, Dogok-Dong, Kangnam-Ku, Seoul 135-720, Republic of Korea
}

(Correspondence should be addressed to CW Ahn; Email: acw@yuhs.ac)

\begin{abstract}
Objective: Osteoprotegerin (OPG) acts as an important regulatory molecule in atherosclerosis. Recent studies report that thiazolidinediones could affect OPG expression. We investigated the relationship between OPG and inflammatory cytokines and the effects of pioglitazone (a PPAR $\gamma$ (PPARG) agonist) versus metformin on serum OPG levels in type 2 diabetic patients.

Design and methods: Sixty-seven type 2 diabetic patients were included in this study. They were assigned to pioglitazone ( $15 \mathrm{mg} /$ day, $n=34$ ) or metformin ( $1000 \mathrm{mg} /$ day, $n=33)$ during 24 weeks. Various anthropometric and metabolic parameters, OPG, interleukin 6 (IL6), C-reactive protein (CRP), adiponectin, and homeostasis model assessment of insulin resistance (HOMA-IR), were measured at baseline and at 6 months of treatment.

Results: Serum OPG levels correlated significantly with fasting plasma glucose (FPG), HbAlc, HOMAIR, IL6, and CRP, and inversely correlated with adiponectin after adjusting for age $(P<0.05)$. Multiple regression analysis showed that FPG, HbAlc, and adioponectin were independently correlated with OPG level. After 6 months of treatment, the reduction in FPG and HbAlc levels was similar between the two groups. Pioglitazone treatment significantly increased body mass index $(P<0.05)$ and waist circumference $(P<0.05)$ and decreased triglycerides $(P<0.05)$ and HOMA-IR $(P<0.01)$. The adiponectin concentration was increased $(P<0.05)$, and OPG and CRP levels were decreased in the pioglitazone group $(P<0.05)$, but were unchanged in the metformin group. The changes in serum OPG in the pioglitazone group showed significant correlation with changes in FPG, HbAlc, and adiponectin.

Conclusions: In type 2 diabetic patients, pioglitazone decreases OPG levels, and this decrease in OPG levels might be associated with the increase in adiponectin.
\end{abstract}

European Journal of Endocrinology 164 69-74

\section{Introduction}

Patients with type 2 diabetes mellitus are at high risk for coronary heart disease, cerebrovascular disease, and peripheral vascular disease, with a two- to six-fold higher risk of developing these disorders than individuals without diabetes (1). These atherosclerotic diseases are common causes of morbidity and mortality among people with diabetes. Atherosclerosis is known to be an inflammatory disease, and many clinical studies have demonstrated a relationship between inflammatory markers and the risk of cardiovascular disease (2).

Osteoprotegerin (OPG) is a glycoprotein belonging to the tumor necrosis factor receptor superfamily, which was originally discovered as an inhibitor of bone resorption. OPG acts as a decoy receptor of the receptor activator of the nuclear factor $\kappa \mathrm{B}$ ligand, thereby inhibiting osteoclastogenesis (3-5). OPG is mainly secreted by bone, but is also secreted by a variety of different tissues including endothelial cells and smooth muscle cells $(6,7)$. Recent studies have shown that OPG also acts as an important regulatory molecule in vascular disease, and increased serum OPG levels are associated with cardiovascular disease in the general population, as well as in diabetic patients $(8,9)$. Epidemiological studies demonstrate a relationship between OPG level and the severity of coronary atherosclerosis $(10,11)$. Based on these data, it is likely that OPG plays an important role in atherosclerosis and could be a marker of atherosclerosis.

Thiazolidinediones (TZDs), including pioglitazone, improve insulin sensitivity and glycemic control in type 2 diabetic patients. In addition, patients treated with TZDs show improved endothelial function, decreased inflammation, and decreased plasma levels 
of free fatty acids, which may have beneficial antiatherogenic effects (12-14). Activation of peroxisome proliferator-activated receptor- $\gamma$ (PPAR- $\gamma$ or PPARG) prevents both OPG expression in human aortic smooth muscle cells (15) and differentiation of mesangial precursors into osteoblastic cells (16). Together, these data suggest that TZDs might reduce OPG plasma levels, as suggested in a more recent study (17). The purposes of this study are to analyze the relationship between OPG and inflammatory cytokines and to investigate the effects of pioglitazone versus metformin on serum OPG levels in type 2 diabetic patients.

\section{Subjects and methods}

\section{Subjects}

Sixty-seven Korean patients with type 2 diabetes mellitus were recruited from the Diabetes Clinic of Kangnam Severance Hospital. The diagnosis of type 2 diabetes was based on a previous history of diabetes or the criteria by the American Diabetes Association's diagnostic guidelines. Patients aged 40-70 years with type 2 diabetes inadequately managed with glimepiride $\geq 2 \mathrm{mg}$ or equivalent dose of other sulfonylurea (e.g. gliclazide MR $30 \mathrm{mg}$ ) and with stable or worsening glycemic control for $\geq 3$ months were eligible if their HbAlc was between 7.0 and $10.0 \%$ and their fasting $C$-peptide was $\geq 1.5 \mathrm{ng} / \mathrm{ml}$ at screening. Exclusions included patients with type 1 diabetes or ketoacidosis, symptomatic heart failure, malignant disease in the previous 10 years, and renal failure.

Subjects were open label randomized into pioglitazone (15 mg/day, $n=34$ ) and metformin (1000 mg/day, $n=33)$ treatment groups. The Institutional Review Board of Yonsei University College of Medicine approved the study protocol, and all of the subjects participated in this study that was carried out following the recommendations of the declaration provided informed consent prior to the start of this study. Patients were enrolled after an initial screening visit. All study measurements were obtained upon entry into the study and at the end of a 24-week observation period.

\section{Clinical characteristics}

Body weight and height were measured in the morning with participants wearing light clothing. Body mass index (BMI) was calculated as weight $(\mathrm{kg}) /$ height $(\mathrm{m})^{2}$. Waist circumference (WC) was measured at the mid point between the lower border of the rib cage and the iliac crest. The patients' past medical histories were evaluated; the duration of diabetes, concomitant diseases, and the drugs currently being taken were assessed. Systolic and diastolic blood pressures (SBP and DBP) were measured after a 5 min rest.

\section{Biochemical parameters}

All measurements were obtained in the morning, after the patient had fasted since midnight. Blood samples were immediately centrifuged, and serum samples were stored at $-70{ }^{\circ} \mathrm{C}$ until laboratory testing. HbAlc was determined by HPLC (Variant II, Bio-Rad). Glucose was measured with a standard glucose oxidase reference method (747 automatic analyzer, Hitachi). Fasting serum insulin was determined by chemiluminescence (RIA kit, Daiichi, Tokyo, Japan). Total cholesterol, high-density lipoprotein (HDL) cholesterol, and triglycerides (TG) were measured with an enzymatic color test (Daiichi, Hitachi 747), and low-density lipoprotein (LDL) cholesterol was calculated according to the Friedewald formula. Insulin resistance was calculated by homeostasis model assessment of insulin resistance (HOMA-IR) analysis, HOMA-IR $=$ fasting insulin $(\mu \mathrm{U} / \mathrm{ml}) \times$ fasting plasma glucose $(\mathrm{mmol} / \mathrm{l}) / 22.5$. Serum OPG levels were measured using a human OPG ELISA kit (Biomedica, Vienna, Austria). C-reactive protein (CRP) levels were measured using a Quantikine CRP kit (R\&D Systems, Minneapolis, MN, USA), and interleukin 6 (IL6) levels were determined using a Quantikine HS IL6 kit (R\&D Systems). Plasma adiponectin levels were measured by ELISA (Mesdia, Seoul, Korea).

Table 1 Baseline characteristics of the study subjects. Data are mean \pm S.D.

\begin{tabular}{lcc}
\hline & $\begin{array}{c}\text { PIO-treated } \\
\text { group }(n=34)\end{array}$ & $\begin{array}{c}\text { MET-treated } \\
\text { group }(n=33)\end{array}$ \\
\hline Sex (M/F) & $18 / 16$ & $17 / 16$ \\
Ages (years) & $62.3 \pm 8.0$ & $63.1 \pm 8.4$ \\
DM duration (years) & $5.1 \pm 5.0$ & $4.9 \pm 5.3$ \\
BMl $\left(\mathrm{kg} / \mathrm{m}^{2}\right)$ & $25.5 \pm 3.8$ & $25.2 \pm 3.0$ \\
WC $(\mathrm{cm})$ & $92.6 \pm 6.2$ & $93.1 \pm 5.4$ \\
SBP $(\mathrm{mmHg})$ & $128.3 \pm 19.7$ & $126.9 \pm 18.8$ \\
DBP $(\mathrm{mmHg})$ & $74.5 \pm 13.4$ & $75.3 \pm 15.6$ \\
FPG $(\mathrm{mmol} / \mathrm{l})$ & $7.7 \pm 1.7$ & $7.5 \pm 1.5$ \\
Insulin $(\mathrm{mU} / \mathrm{l})$ & $10.2 \pm 2.7$ & $9.9 \pm 2.5$ \\
HbAlc $(\%)$ & $8.3 \pm 0.3$ & $8.2 \pm 0.4$ \\
Creatinine $(\mu \mathrm{mol} / \mathrm{l})$ & $86.0 \pm 12.4$ & $85.3 \pm 14.7$ \\
TC $(\mathrm{mmol} / \mathrm{l})$ & $4.8 \pm 0.7$ & $4.7 \pm 0.7$ \\
TG $(\mathrm{mmol} / \mathrm{l})$ & $1.9 \pm 0.7$ & $1.8 \pm 0.8$ \\
HDL-C $(\mathrm{mmol} / \mathrm{l})$ & $1.1 \pm 0.2$ & $1.2 \pm 0.2$ \\
LDL-C $(\mathrm{mmol} / \mathrm{l})$ & $2.9 \pm 0.6$ & $2.8 \pm 0.6$ \\
AST $(\mathrm{IU} / \mathrm{l})$ & $23.8 \pm 6.1$ & $23.1 \pm 8.2$ \\
ALT $(\mathrm{IU} / \mathrm{l})$ & $25.8 \pm 11.1$ & $25.3 \pm 10.6$ \\
HOMA-IR & $3.49 \pm 1.62$ & $3.46 \pm 1.48$ \\
Adiponectin $(\mu \mathrm{g} / \mathrm{ml})$ & $5.48 \pm 3.24$ & $5.71 \pm 4.21$ \\
OPG $(\mathrm{pmol} / \mathrm{l})$ & $3.73 \pm 1.12$ & $3.65 \pm 1.20$ \\
IL6 $(\mathrm{pg} / \mathrm{ml})$ & $1.78 \pm 1.32$ & $1.73 \pm 1.10$ \\
CRP $(\mu \mathrm{g} / \mathrm{ml})$ & $1.73 \pm 1.30$ & $1.74 \pm 1.07$ \\
\hline
\end{tabular}

PIO, pioglitazone; MET, metformin; BMI, body mass index; WC, waist circumference; FPG, fasting plasma glucose; TC, total cholesterol; TG, triglyceride; HDL-C, high-density lipoprotein cholesterol; LDL-C, low-density lipoprotein cholesterol; SBP, systolic blood pressure; DBP, diastolic blood pressure; $A S T$, aspartate aminotransferase; ALT, alanine aminotransferase; HOMA-IR, homeostasis model assessment of insulin resistance; OPG, osteoprotegerin; IL6, interleukin 6; CRP, C-reactive protein. 
Table 2 Correlations between OPG and other variables $\left(r^{1}\right)$ and after correction for age $\left(r^{2}\right)$.

\begin{tabular}{lcc}
\hline & $\boldsymbol{r}^{\mathbf{1}}$ & $\boldsymbol{r}^{\mathbf{2}}$ \\
\hline Age & $0.25^{\star}$ & $\mathrm{NA}$ \\
BMI & 0.17 & 0.14 \\
WC & 0.09 & 0.07 \\
SBP & 0.11 & 0.09 \\
DBP & 0.11 & 0.10 \\
FPG & $0.28^{\dagger}$ & $0.26^{\dagger}$ \\
Insulin & $0.15^{\mathrm{a}}$ & $0.12^{\mathrm{a}}$ \\
HbAlc & $0.23^{\dagger}$ & $0.20^{\star}$ \\
HOMA-IR & $0.21^{*, \mathrm{a}}$ & $0.16^{*, \mathrm{a}}$ \\
Creatinine & 0.09 & 0.02 \\
TC & 0.18 & 0.16 \\
TG & $0.08^{\mathrm{a}}$ & $0.07^{\mathrm{a}}$ \\
HDL-C & -0.17 & -0.12 \\
LDL-C & 0.06 & 0.05 \\
AST & 0.06 & 0.03 \\
ALT & 0.05 & 0.04 \\
Adiponectin & $-0.27^{\dagger, \mathrm{a}}$ & $-0.22^{\dagger, \mathrm{a}}$ \\
IL6 & $0.15^{\star, a}$ & $0.12^{*, \mathrm{a}}$ \\
CRP & $0.18^{\star, a}$ & $0.11^{*, \mathrm{a}}$ \\
\hline
\end{tabular}

${ }^{*} P<0.05,{ }^{\dagger} P<0.01$.

${ }^{\text {aPearson }}$ correlation was used after logarithmic transformation for these variables.

\section{Statistical analysis}

Data are expressed as the mean \pm s.D. Statistical analysis was performed with unpaired or paired Student's $t$-tests. Pearson's correlation coefficients were used to estimate the correlations between serum OPG concentration, physical measurements, clinical characteristics, and insulin resistance. The linear correlations were analyzed after logarithmic transformation for the variables not normally distributed. Stepwise multiple linear regression analysis was performed to analyze the influence of different factors on OPG. Statistical analyses were conducted using SPSS for Windows, version 11.0 (SPSS, Inc., Chicago, IL, USA), and $P<0.05$ was considered statistically significant.

\section{Results}

The two treatment groups were similar with respect to age, gender distribution, duration of diabetes mellitus, HbAlc, BMI, lipid profile, SBP, DBP, baseline insulin sensitivity, adiponectin, OPG, IL6, and CRP (Table 1). According to baseline data, serum OPG levels in diabetic patients correlated significantly with age, fasting plasma glucose (FPG), HbAlc, HOMA-IR, adiponectin, IL6, and CRP. These correlations persisted after adjustment for age (Table 2). Multiple regression analysis showed that FPG $(\beta=0.16, P<0.01)$, HbAlc $(\beta=0.11, P=0.04)$, and adioponectin $(\beta=-0.13$, $P=0.03)$ were independently correlated with OPG levels. The adjusted $r^{2}$ was $21.3 \%$.

After 6 months of treatment, there were no differences in the improvements of FPG and HbAlc from baseline by both drugs. Treatment with pioglitazone significantly increased BMI and $\mathrm{WC}$ and decreased insulin, TG levels, and HOMA-IR. Plasma adiponectin concentrations were increased in the pioglitazone group but were unchanged in the metformin group. Plasma levels of OPG and CRP decreased in the pioglitazone group but were unchanged in the metformin group (Table 3 and Fig. 1).

Table 3 Effect of each agent on clinical and biochemical characteristics. Data are mean \pm S.D.

\begin{tabular}{|c|c|c|c|c|}
\hline & \multicolumn{2}{|c|}{ PIO-treated group $(n=34)$} & \multicolumn{2}{|c|}{ MET-treated group $(n=33)$} \\
\hline & Before & After & Before & After \\
\hline BMI $\left(\mathrm{kg} / \mathrm{m}^{2}\right)$ & $25.5 \pm 3.8$ & $26.3 \pm 3.2^{*}$ & $25.2 \pm 3.0$ & $24.8 \pm 2.9$ \\
\hline WC $(\mathrm{cm})$ & $92.6 \pm 6.2$ & $96.9 \pm 7.3^{\star}$ & $93.1 \pm 5.4$ & $92.2 \pm 6.6$ \\
\hline $\mathrm{SBP}(\mathrm{mmHg})$ & $128.3 \pm 19.7$ & $130.2 \pm 19.5$ & $126.9 \pm 18.8$ & $129.4 \pm 23.1$ \\
\hline $\mathrm{DBP}(\mathrm{mmHg})$ & $74.5 \pm 13.4$ & $76.5 \pm 16.7$ & $75.3 \pm 15.6$ & $78.4 \pm 15.9$ \\
\hline $\mathrm{FPG}(\mathrm{mmol} / \mathrm{l})$ & $7.7 \pm 1.7$ & $6.3 \pm 1.7^{\dagger}$ & $7.5 \pm 1.5$ & $6.5 \pm 1.2^{\dagger}$ \\
\hline Insulin (mU/l) & $10.2 \pm 2.7$ & $5.8 \pm 2.5^{\dagger}$ & $9.9 \pm 2.5$ & $9.0 \pm 1.8$ \\
\hline HbAlc (\%) & $8.3 \pm 0.3$ & $7.5 \pm 0.6^{*}$ & $8.2 \pm 0.4$ & $7.4 \pm 0.4^{*}$ \\
\hline Creatinine $(\mu \mathrm{mol} / \mathrm{l})$ & $86.0 \pm 12.4$ & $85.6 \pm 11.8$ & $85.3 \pm 14.7$ & $86.1 \pm 10.7$ \\
\hline $\mathrm{TC}(\mathrm{mmol} / \mathrm{l})$ & $4.8 \pm 0.7$ & $4.5 \pm 0.6$ & $4.7 \pm 0.7$ & $4.6 \pm 0.5$ \\
\hline $\mathrm{TG}(\mathrm{mmol} / \mathrm{l})$ & $1.9 \pm 0.7$ & $1.4 \pm 0.8^{\star}$ & $1.8 \pm 0.8$ & $1.7 \pm 0.7$ \\
\hline HDL-C (mmol/l) & $1.1 \pm 0.2$ & $1.3 \pm 0.4$ & $1.2 \pm 0.2$ & $1.1 \pm 0.2$ \\
\hline LDL-C (mmol/l) & $2.9 \pm 0.6$ & $2.5 \pm 0.5$ & $2.8 \pm 0.6$ & $2.4 \pm 0.5$ \\
\hline AST (IU/I) & $23.8 \pm 6.1$ & $24.3 \pm 5.8$ & $23.1 \pm 8.2$ & $23.5 \pm 6.4$ \\
\hline ALT (IU/I) & $25.8 \pm 11.1$ & $25.5 \pm 8.9$ & $25.3 \pm 10.6$ & $24.7 \pm 9.5$ \\
\hline HOMA-IR & $3.49+1.62$ & $1.63+1.01^{\dagger}$ & $3.46+1.48$ & $2.86+1.55$ \\
\hline Adiponectin $(\mu \mathrm{g} / \mathrm{ml})$ & $5.48 \pm 3.24$ & $9.78 \pm 6.26^{\dagger}$ & $5.71 \pm 4.21$ & $6.95 \pm 4.27$ \\
\hline $\mathrm{OPG}(\mathrm{pmol} / \mathrm{l})$ & $3.73 \pm 1.12$ & $2.54 \pm 0.78^{\star}$ & $3.65 \pm 1.20$ & $3.34 \pm 0.83$ \\
\hline IL6 (pg/ml) & $1.78 \pm 1.32$ & $1.50 \pm 0.97$ & $1.73 \pm 1.10$ & $1.39 \pm 0.39$ \\
\hline CRP $(\mu \mathrm{g} / \mathrm{ml})$ & $1.73 \pm 1.30$ & $1.23 \pm 0.75^{\star}$ & $1.74 \pm 1.07$ & $1.52 \pm 0.69$ \\
\hline
\end{tabular}

${ }^{\star} P<0.05$ for comparison of data before and after treatment. ${ }^{\dagger} P<0.01$ for comparison of data before and after treatment. 


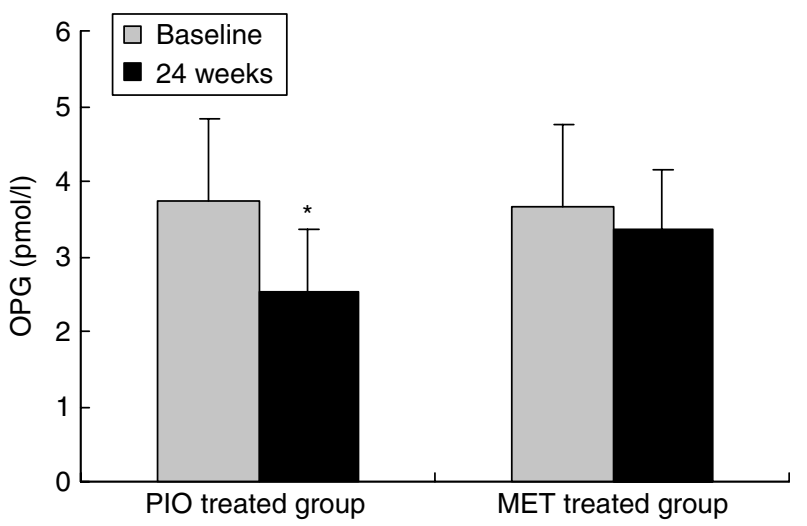

Figure 1 Effects of pioglitazone and metformin at 24 weeks on serum OPG ( $\left.{ }^{\star} P<0.05\right)$. $P$ values are Student's $t$-test, showing a significant decrease for the pioglitazone group.

The change in OPG and other variables was calculated as the difference in values; the absolute changes in serum OPG in the pioglitazone group showed significant correlation with changes in FPG, HbAlc, and adiponectin (Table 4).

\section{Discussion}

In this study, we showed that serum OPG level inversely correlates with adiponectin, and pioglitazone treatment increases adiponectin and decreases OPG and CRP levels. Moreover, changes in serum OPG in the pioglitazone group showed significant correlations with changes in FPG, HbAlc, and adiponectin.

Several recent studies have identified a relationship between OPG and human vascular biology. Browner et al. (18) reported that a high serum OPG level is associated with increased cardiovascular mortality, and Xiang et al. (19) demonstrated its relationship with endothelial dysfunction, which is an important early event in atherosclerosis (20). In addition, patients with type 2 diabetes, who are at a two- to six-fold increased risk for cardiovascular disease (1), were shown to have a higher serum OPG level compared with subjects without diabetes $(19,21)$. Moreover, Avignon et al. (22) found that OPG is an independent predictor of coronary artery disease in patients with type 2 patients.

Hyperglycemia and elevated HbAlc are well known cardiovascular risk factors, and we found that plasma OPG levels positively correlated with FPG and HbAlc, in agreement with previous studies $(19,21)$. As expected, based on results of previous studies $(21,23)$, our results also confirmed a positive relationship between OPG and HOMA-IR.

Inflammation plays a major role in diabetes-induced atherosclerosis (24). CRP is an inflammatory marker, which is produced predominantly by hepatocytes under the influence of cytokines, and the inflammatory cytokine IL6, which is secreted by adipose tissue, stimulates CRP production in the liver. In this study, we showed a positive relationship between OPG and both CRP and IL6 in type 2 diabetes, consistent with previous reports that serum OPG levels are correlated with CRP $(21,23)$ and IL6 (21). Adiponectin is an important adipocytokine with anti-inflammatory and anti-atherogenic properties, which modulates insulin resistance (25). Clinical studies have shown that adiponectin levels are lower in individuals with cardiovascular disease (26), but the relationship between adiponectin and OPG remains unclear. Gannagé-Yared et al. (23) reported no significant association between adiponectin and OPG in obese and non-obese populations. Another study showed a positive association between adiponectin and OPG in an aging male population but did not show a correlation between OPG and coronary artery disease (27). In contrast, Hofsø et al. (28) reported that OPG levels are negatively correlated with adiponectin levels. In this study, we report an inverse correlation between adiponectin and OPG levels in type 2 diabetes. Sodi et al. (29) showed that adiponectin may negatively affect osteoblast production of OPG and in vitro studies have shown that adiponectin inhibits OPG production in human osteoblasts (30). Jurimae et al. (31) suggested that adiponectin could be involved in bone weakening.

TZDs act as agonists of PPAR $-\gamma$ and are powerful insulin sensitizers, which have been used as antidiabetic agents. PPAR- $\gamma$ agonists, such as pioglitazone, cause a marked increase in adiponectin gene expression in adipocytes and also have anti-inflammatory and antiatherogenic properties (32). In this study, patients with type 2 diabetes, who were treated with pioglitazone and metformin, had comparable FPG and HbAlc values before and after the study, thus, glycemic control, as determined by FPG and HbAlc, did not differ between the groups. Treatment with pioglitazone for 24 weeks increased adiponectin levels and decreased levels of CRP and OPG in patients with type 2 diabetes, and this effect was presumably independent of glycemic control.

Several limitations of this study need to be considered, the major one being the small number of patients involved and the low dose of pioglitazone used. In addition, we showed data for only 24 weeks of treatment with pioglitazone, which may not necessarily reflect the results of long-term treatment. Third, due to the lack of normal glucose tolerance control group, we could not analyze the relationship between OPG and metabolic parameters and inflammatory cytokines in the control

Table 4 Correlations between changes in OPG and changes in other variables in the pioglitazone-treated group.

\begin{tabular}{lrr}
\hline & \multicolumn{1}{c}{$\boldsymbol{r}$} & \multicolumn{1}{c}{$\boldsymbol{P}$} \\
\hline FPG & 0.27 & $<0.01$ \\
HbAlc & 0.12 & 0.04 \\
Adiponectin & -0.21 & 0.03 \\
\hline
\end{tabular}


group and compare them between the normal control group and type 2 diabetic patients. Finally, because endothelial or osteoblast OPG expression was not measured, the precise relationship between serum OPG levels and vascular integrity and bone metabolism could not evaluated.

In conclusion, pioglitazone decreases OPG level, and this decrease in OPG level is associated with the increase in adiponectin. Further studies are needed to elucidate the observed relationships.

\section{Declaration of interest}

The authors declare that there is no conflict of interest that could be perceived as prejudicing the impartiality of the research reported.

\section{Funding}

This study was supported by a faculty research grant of Yonsei University College of Medicine for 2007 and Yonsei University College of Medicine, Internal Medicine Research Grant 2007.

\section{References}

1 Kannel WB \& McGee DL. Diabetes and cardiovascular disease; the Framingham study. Journal of the American Medical Association 1979241 2035-2038. (doi:10.1001/jama.241.19.2035)

2 Willerson JT \& Ridker PM. Inflammation as a cardiovascular risk factor. Circulation 2004109 2-10. (doi:10.1161/01.CIR. $0000122867.89751 .59)$

3 Hofbauer LC \& Heufelder AE. The role of receptor activator of nuclear factor-kB ligand and osteoprotegerin in the pathogenesis and treatment of metabolic bone diseases. Journal of Clinical Endocrinology and Metabolism 200085 2355-2363. (doi:10. $1210 /$ jc.85.7.2355)

4 Tsuda E, Goto M, Mochizuki S, Yano K, Kobayashi F, Morinaga T \& Higashio K. Isolation of a novel cytokine from human fibroblasts that specifically inhibits osteoclastogenesis. Biochemical and Biophysical Research Communications 1997234 137-142. (doi:10. 1006/bbrc.1997.6603)

5 Kwon BS, Wang S, Udagawa N, Haridas V, Lee ZH, Kim KK, Oh KO, Greene J, Li Y, Su J, Gentz R, Aggarwal BB \& Ni J. TR1, a new member of the tumor necrosis factor receptor superfamily, induces fibroblast proliferation and inhibits osteoclastogenesis and bone resorption. FASEB Journal $1998 \mathbf{1 2}$ 845-854.

6 Hofbauer LC, Shui C, Riggs BL, Dunstan CR, Spelsberg TC, O'Brien T \& Khosla S. Effects of immunosuppressants on receptor activator of NF-B ligand and osteoprotegerin production by human osteoblastic and coronary artery smooth muscle cells. Biochemical and Biophysical Research Communications 2001280 334-339. (doi:10.1006/bbrc.2000.4130)

7 Collin-Osdoby P, Rothe L, Anderson F, Nelson M, Maloney W \& Osdoby P. Receptor activator of NF-B and osteoprotegerin expression by human microvascular endothelial cells, regulation by inflammatory cytokines, and role in human osteoclastogenesis. Journal of Biological Chemistry 2001276 20659-20672. (doi:10. 1074/jbc.M010153200)

8 Kiechl S, Schett G, Wenning G, Redlich K, Oberhollenzer M, Mayr A, Santer P, Smolen J, Poewe W \& Willeit J. Osteoprotegerin is a risk factor for progressive atherosclerosis and cardiovascular disease. Circulation 2004109 2175-2180. (doi:10.1161/01.CIR. 0000127957.43874.BB)

9 Knudsen ST, Foss CH, Poulsen PL, Andersen NH, Mogensen CE \& Rasmussen LM. Increased plasma concentrations of osteoprotegerin in type 2 diabetic patients with microvascular complications. European Journal of Endocrinology 2003149 39-42. (doi:10.1530/eje.0.1490039)

10 Jono S, Ikari Y, Shioi A, Mori K, Miki T, Hara K \& Nishizawa Y. Serum osteoprotegerin levels are associated with the presence and severity of coronary artery disease. Circulation $2002 \mathbf{1 0 6}$ 1192-1194. (doi:10.1161/01.CIR.0000031524.49139.29)

11 Schoppet M, Sattler AM, Schaefer JR, Herzum M, Maisch B \& Hofbauer LC. Increased osteoprotegerin serum levels in men with coronary artery disease. Journal of Clinical Endocrinology and Metabolism 200388 1024-1028. (doi:10.1210/jc.2002020775)

12 Yki-Jarvinen H. Thiazolidinediones. New England Journal of Medicine 2004351 1106-1118. (doi:10.1056/NEJMra041001)

13 Barbier O, Torra IP, Duguay Y, Blanquart C, Fruchart JC, Glineur C \& Staels B. Pleiotropic actions of peroxisome proliferator-activated receptors in lipid metabolism and atherosclerosis. Arteriosclerosis, Thrombosis, and Vascular Biology 200222 717-726. (doi:10. 1161/01.ATV.0000015598.86369.04)

14 Martens FM, Visseren FL, Lemay J, De Koning EJ \& Rabelink TJ. Metabolic and additional vascular effects of thiazolidinediones. Drugs 200262 1463-1480. (doi:10.2165/00003495-200262 100-00004)

15 Fu M, Zhang J, Lin YG, Zhu X, Willson TM \& Chen YE. Activation of peroxisome proliferator-activated receptor [gamma] inhibits osteoprotegerin gene expression in human aortic smooth muscle cells. Biochemical and Biophysical Research Communications 2002 294 597-601. (doi:10.1016/S0006-291X(02)00533-8)

16 Lecka-Czernik B, Gubrij I, Moerman EJ, Kajkenova O, Lipschitz DA, Manolagas SC \& Jilka RL. Inhibition of Osf $2 / \mathrm{Cbfa} 1$ expression and terminal osteoblast differentiation by PPAR gamma. Journal of Biological Chemistry 199974 357-371. (doi:10.1002/(SICI) 1097-4644(19990901)74:3<357::AID-JCB5 > 3.0.CO;2-7)

17 Sultan A, Avignon A, Galtier F, Piot C, Mariano-Goulart D, Dupuy AM \& Cristol JP. Osteoprotegerin, thiazolidinediones treatment, and silent myocardial ischemia in type 2 diabetic patients. Diabetes Care 200831 593-595. (doi:10.2337/dc071771)

18 Browner WS, Lui LY \& Cummings SR. Associations of serum osteoprotegerin levels with diabetes, stroke, bone density, fracture, and mortality in elderly women. Journal of Clinical Endocrinology and Metabolism 200186 631-637. (doi:10.1210/ jc.86.2.631)

19 Xiang GD, Xu L, Zhao LS, Yue L \& Hou J. The relationship between plasma osteoprotegerin and endothelium dependent arterial dilation in type 2 diabetes. Diabetes 200655 2126-2131. (doi:10.2337/db06-0231)

20 Boneti PO, Lerman LO \& Lerman A. Endothelial dysfunction, a marker of atherosclerotic risk. Arteriosclerosis, Thrombosis, and Vascular Biology 200323 168-175. (doi:10.1161/01.ATV. 0000051384.43104.FC)

21 Kim SM, Lee J, Ryu OH, Lee KW, Kim HY, Seo JA, Kim SG, Kim NH, Baik SH, Choi DS \& Choi KM. Serum osteoprotegerin levels are associated with inflammation and pulse wave velocity. Clinical Endocrinology 200563 594-598. (doi:10.1111/j.1365-2265. 2005.02390.x)

22 Avignon A, Sultan A, Piot C, Elaerts S, Cristol JP \& Dupuy AM. Osteoprotegerin is associated with silent coronary artery disease in high-risk but asymptomatic type 2 diabetic patients. Diabetes Care 200528 2176-2180. (doi:10.2337/diacare.28.9.2176)

23 Gannagé-Yared MH, Yaghi C, Habre B, Khalife S, Noun R, GermanosHaddad M \& Trak-Smayra V. Osteoprotegerin in relation to body weight, lipid parameters insulin sensitivity, adipocytokines, and C-reactive protein in obese and non-obese young individuals: results from both cross-sectional and interventional study. European Journal of Endocrinology 2008158 353-359. (doi:10.1530/EJE-07-0797)

24 Libby P \& Ridker PM. Inflammation and atherosclerosis: role of C-reactive protein in risk assessment. American Journal of Medicine 2004116 9S-16S. (doi:10.1016/j.amjmed.2004.02.006) 
25 Gil-Campos M, Canete R \& Gil A. Adiponectin, the missing link in insulin resistance and obesity. Clinical Nutrition 200423 963-974. (doi:10.1016/j.clnu.2004.04.010)

26 Ouchi N, Kihara S, Arita Y, Maeda K, Kuriyama H, Okamoto Y, Hotta K, Nishida M, Takahashi M, Nakamura T, Yamashita S, Funahashi T \& Matsuzawa Y. Novel modulator for endothelial adhesion molecules: adipocyte-derived plasma protein adiponectin. Circulation $19991002473-2476$.

27 Gannagé-Yared MH, Fares F, Semaan M, Khalife S \& Jambart S. Circulating osteoprotegerin is correlated with lipid profile, insulin sensitivity, adiponectin and sex steroids in an ageing male population. Clinical Endocrinology 200664 652-658. (doi:10. 1111/j.1365-2265.2006.02522.x)

28 Hofsø D, Ueland T, Hager H, Jenssen T, Bollerslev J, Godang K, Aukrust P, Røislien J \& Hjelmesaeth J. Inflammatory mediators in morbidly obese subjects: associations with glucose abnormalities and changes after oral glucose. European Journal of Endocrinology 2009161 451-458. (doi:10.1530/EJE-09-0421)

29 Sodi R, Hazell MJ, Durham BH, Rees C, Ranganath LR \& Fraser WD. The circulating concentration and ratio of total and high molecular weight adiponectin in post-menopausal women with and without osteoporosis and its association with body mass index and biochemical markers of bone metabolism. Clinical Biochemistry 200942 1375-1380. (doi:10.1016/j.clinbiochem.2009.06.003)

30 Luo XH, Guo LJ, Xie H, Yuan LQ, Wu XP, Zhou HD \& Liao EY. Adiponectin stimulates RANKL and inhibits OPG expression in human osteoblasts through the MAPK signalling pathway. Journal of Bone and Mineral Research 200621 1648-1658. (doi:10.1359/jbmr.060707)

31 Jurimae J, Rembel K, Jurimae T \& Rehand M. Adiponectin is associated with bone mineral density in perimenopausal women. Hormone and Metabolic Research 200537 297-302. (doi:10.1055/ s-2005-861483)

32 Pfutzner A, Marx N, Lubben G, Langenfeld M, Walcher D, Konrad T \& Forst T. Improvement of cardiovascular risk markers by pioglitazone is independent from glycemic control: results from the pioneer study. Journal of the American College of Cardiology 2005 45 1925-1931. (doi:10.1016/j.jacc.2005.03.041)

Received 6 October 2010

Accepted 20 October 2010 